University of Nebraska - Lincoln

DigitalCommons@University of Nebraska - Lincoln

Publications of the University of Nebraska

Public Policy Center

Public Policy Center, University of Nebraska

2020

\title{
Examining How Rural Ecological Contexts Influence Children's Early Learning Opportunities
}

Iheoma U. Iruka

HighScope Educational Research Foundation, iruka@unc.edu

Mark DeKraai

University of Nebraska Public Policy Center

Janell Walther

University of Nebraska Public Policy Center, jwalther2@nebraska.edu

Susan M. Sheridan

University of Nebraska - Lincoln, ssheridan2@unl.edu

Tarik Abdel-Monem

University of Nebraska Public Policy Center, tabdelmonem@nebraska.edu

Follow this and additional works at: https://digitalcommons.unl.edu/publicpolicypublications

Part of the Other Public Affairs, Public Policy and Public Administration Commons, Other Social and Behavioral Sciences Commons, Public Affairs Commons, Public Policy Commons, and the Social Policy Commons

Iruka, Iheoma U.; DeKraai, Mark; Walther, Janell; Sheridan, Susan M.; and Abdel-Monem, Tarik, "Examining How Rural Ecological Contexts Influence Children's Early Learning Opportunities" (2020). Publications of the University of Nebraska Public Policy Center. 194.

https://digitalcommons.unl.edu/publicpolicypublications/194

This Article is brought to you for free and open access by the Public Policy Center, University of Nebraska at DigitalCommons@University of Nebraska - Lincoln. It has been accepted for inclusion in Publications of the University of Nebraska Public Policy Center by an authorized administrator of DigitalCommons@University of Nebraska - Lincoln. 


\title{
Examining How Rural Ecological Contexts Influence Children's Early Learning Opportunities
}

\author{
Iheoma U. Iruka, ${ }^{1}$ Mark DeKraai, ${ }^{2}$ Janell Walther, ${ }^{2}$ Susan M. Sheridan, ${ }^{3}$ and \\ Tarik Abdel-Monem²
}

1. HighScope Educational Research Foundation, USA

2. University of Nebraska Public Policy Center, USA

3. University of Nebraska-Lincoln, USA

Corresponding author - Iheoma U. Iruka, email iiruka@highscope.org

\begin{abstract}
According to Bronfenbrenner's bioecological theory (Bronfenbrenner \& Evans, 2000), children's early development and learning are influenced by multiple systems, including the microsystem (e.g., family poverty level), mesosystem (e.g., home-school partnership), exosystem (e.g., community type, early education policies), and macrosystem (e.g., rural culture). Given the lack of early education studies focused on rural communities, we sought to explore how these ecological systems are linked to children's early learning experiences, with a particular focus on educators' perceptions of how these ecosystems influence children's learning environments and opportunities. Based on interviews and focus groups with school leaders, educators, and parents in 10 rural school districts, we found that children in one rural state experienced diversity in ecological systems that may impact their opportunities for learning. In particular, there was a range in the level of familial poverty, early education access, family-school engagement, available community resources, and cultural diversity in these rural communities. Implications for policies and practices to support children's early learning in rural communities in light of their unique challenges and assets are discussed.
\end{abstract}

Keywords: rural, pre-K, family engagement, ecological system, poverty 


\section{Examining how rural ecological contexts influence children's early learning}

Research tells us that the brain develops most rapidly in the earliest years and that enriching early learning experiences are critical for the long-term success of children (Shonkoff, Garner, \& The Committee on Psychosocial Aspects of Child Family Health, C.o.E.C., 2012). Long-term benefits and outcomes both for the child and society are associated with highquality early learning experiences (Vandell et al., 2010). Findings regarding the importance of stimulating early learning environments have resulted in the proliferation of local and state programs that serve children from birth to age 5 . Whereas children who attend preKindergarten (pre-K) have marginally better literacy and numeracy skills relative to those who do not (Phillips et al., 2017), much is yet to be learned about the myriad factors influencing child outcomes. Most research attention has been focused on identifying proximal impacts on children's learning, such as the quality of instruction in classrooms (Burchinal, 2018) and stimulating experiences at home (Jeon, Buettner, \& Hur, 2014). Much less attention has been afforded to other ecological factors, such as broad community and policy contexts.

One systemic variable often overlooked in efforts to pinpoint impacts on development is the geographic locale within which children live and learn. Specifically, the experiences and opportunities available to children in rural community settings may have notable, albeit indirect, effects on early learning. The manner in which a rural setting intersects with immediate child, family, and school factors has not been adequately explored. An exception is the Family Life Project (FLP; Vernon-Feagans \& Cox, 2013), which provides the most robust longitudinal study shaping our understanding of early development of young children growing up in poor rural communities in North Carolina and Pennsylvania. The primary goal of FLP is to develop a better understanding of how growing up in rural areas might influence the development of children and their families, including their childcare experiences. The current study focuses on a different rural context not represented in FLP - the Midwest with particular attention to the public school system.

Research that expands our understanding of how rural ecosystems interact to shape children's early learning opportunities is sorely needed. In this study, we use data from community stakeholders, including school leaders, educators, and parents, to provide a rich qualitative exploration of how rurality intersects with children's early learning experiences, examining the implications of geographic setting on funding, access, family engagement, professional development, and community resources.

\section{Theoretical framework}

Bronfenbrenner's bioecological theory guides the present study. The bioecological framework places emphasis on the multiple systems that have an impact on children's development; each system is embedded within and has an impact on the others in reciprocal ways (Bronfenbrenner \& Evans, 2000). The microsystem is most proximal to children's development and includes the immediate context of home and school/preschool programs. Examples of microsystemic variables are family poverty level, mobility, and the early childhood learning environment, especially pre- $\mathrm{K}$. The mesosystem is the connection across micro- 
systems, such as relationships between families and their child's educators and other connections between home and school. The exosystem is the social environment that indirectly influences a child's development through a community's geographic locale (e.g., rural, urban), density, demography, transportation, and economy. Macrosystems are represented by the values, norms, customs, and policies exhibited within these systems. Our interest is in understanding how various systems (i.e., micro-, meso-, and macro-) manifest in a rural context (i.e., exosystem). For example, we will examine how the rural context may be related to availability of early learning opportunities (microsystem) and the home-school connection (mesosytem), among others. Figure 1 provides a visual of the key aspects of the ecological systems we will examine in this study.

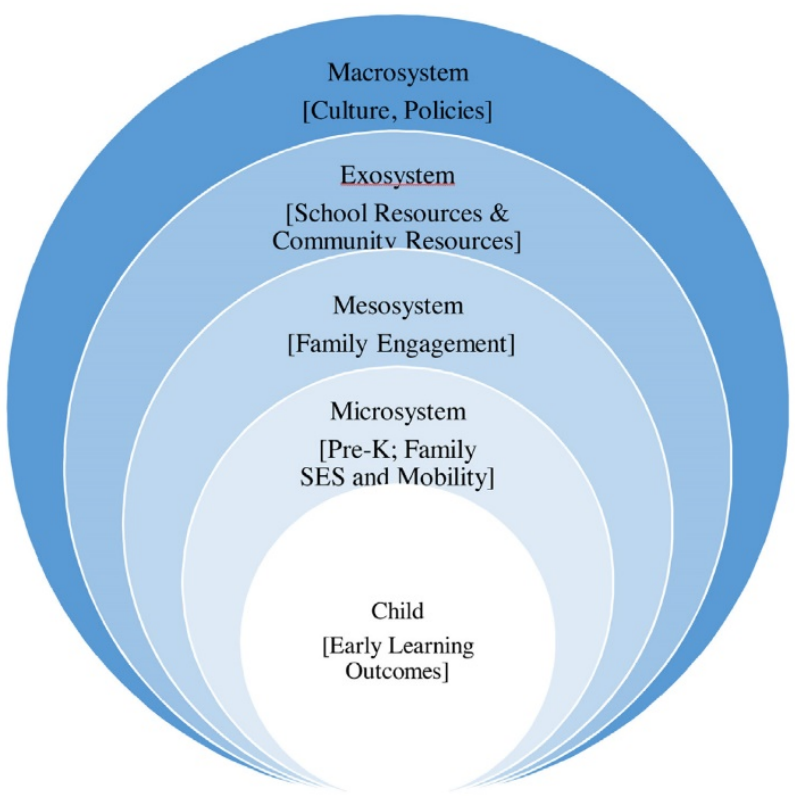

Figure 1. Key focus areas within the ecological systems framework.

\section{Rural context}

The National Center for Education Statistics categorizes all school districts into one of 12 categories within four locale codes (city, suburb, town, rural) using an "urban-centric" classification system. The categories rely on concepts used by the Census Bureau to define an area's urbanicity; urbanized centers are core areas with populations of $\geq 50,000$ while urban clusters are defined by populations between 2,500 and 50,000. Rural areas do not lie inside an urbanized area or urban cluster. The two urban school districts involved in the study are located in a large principal city. The ten rural school districts are characterized as Rural Remote (2); Town Remote (7), and Town Distant (1).

Sometimes population density is the defining concern, in other cases it is geographic isolation. Regardless, rurality is a potentially significant exosystemic factor that influences children's learning and development in many ways. One-third of schools in the United 
States are rural, and 19\% of the nation's children, or approximately 9 million children, are in rural school settings (Showalter, Klein, Johnson, \& Hartman, 2017). In 2015, the total population in nonmetro counties (i.e., rural communities) was approximately 46.2 million with $14 \%$ of US residents spread across $72 \%$ of the nation's land area. The population growth rates in nonmetro areas have been significantly lower than in metro areas since the mid-1990s, and the gap has widened. This lower population-level may be one of the reasons for the limited research on rural communities, and specifically research on young children in rural communities.

Rural residents are becoming more highly educated; however, they are doing so at a slower rate and still experience more unemployment or underemployment relative to their urban counterparts (Economic Research Service, 2017). The persistent lack of availability of highly qualified teachers and the number of families living in low-resourced households directly impact rural children's learning opportunities and may ultimately affect their social and academic outcomes (Monk, 2007).

Many strengths characterize the rural experience. Close ties among families and communities, a sense of "doing what it takes" among educators, small class sizes, and desirable student-teacher ratios are some of the assets of rural settings (Miller \& Votruba-Drzal, 2013). Furthermore, rural communities benefit from a strong emphasis on relationships and religion, lessened exposure to crime, increased home ownership, and greater access to nature and green spaces (Durham \& Smith, 2006; Miller \& Votruba-Drzal, 2013). However, relative to urban communities, rural communities are more isolated and geographically distant from resources and services, such as pre-K programs, jobs, social services, and recreational opportunities. The 2016 Child Care Aware America report (Dobbins, Tercha, McCready, \& Liu, 2016) found that childcare deserts (defined as areas or communities with limited or no access to quality childcare) were prevalent in rural communities. Choices for childcare in rural communities primarily were limited to home-based providers. Furthermore, although teachers in rural areas are generally satisfied, there is high turnover due to compensation levels that are much lower than in urban areas, including in early childhood programs (Monk, 2007).

With some exceptions (cf. Vernon-Feagans \& Cox, 2013), there is a dearth of research focused on the influence of rural context on children's early schooling and learning experiences. There is a need to understand how ecological systems operate in rural contexts, subsequently affecting children's early learning opportunities. We examine salient factors at each of the levels and their manifestation in one rural state.

\section{Rural ecological factors and children's early learning opportunities}

In line with the bioecological framework, we seek to understand educators' perceptions of how the rural context influences children's early learning experiences. We provide a review illustrating the links between aspects of the rural ecological systems and children's early learning opportunities. 


\subsection{Microsystem}

In the present study, we focus on microsystems that are proximal to children's early learning in rural communities, including access to pre-K programs and family economic status and mobility.

\subsubsection{Pre-Kindergarten access}

As a way to mitigate the detrimental effect of poverty, early childhood programs (particularly pre-K for 4-year-olds) have proliferated across the educational landscape. There is now convincing evidence pointing to the significant links between pre-K programs and children's academic skills, relative to home-based care (e.g., Weiland, Ulvestad, Sachs, \& Yoshikawa, 2013). Likewise, there is value and utility in other early childhood programs, such as center- and home-based childcare programs serving children starting at birth. Well-implemented high-quality pre-K has been found to be effective for enhancing children's cognitive and language outcomes, especially for children who are from disadvantaged households, or who are dual language learners (Phillips et al., 2017). As many children in rural communities live in low socioeconomic conditions, it is plausible that they may benefit from access to pre-K programs. However, in their report on rural pre-K, Smith, Patterson, and Doggett (2008) found that only approximately $50 \%$ of rural children had access to center-based preschool programs. ${ }^{1}$ More recently, Malik et al. (2018) found that $55 \%$ of children under age 5 in rural communities live in childcare deserts compared to one-third of children in urban communities, translating to lower school readiness for rural children compared to their urban peers. Children in rural districts were found to be $15 \%$ less likely to begin kindergarten with early literacy skills, and 50\% less likely to possess beginning sound recognition than urban children. Children from rural communities were also $60 \%$ more likely to require special education placement than children from nonrural areas. Smith, Patterson, and Doggett (2008) and Malik et al. (2018) postulate that these pre-K challenges in rural communities are likely due to several factors, including: (1) a limited local tax base that is insufficient to fund programs; (2) low-wage jobs and difficulty affording the cost of pre-K; (3) sometimes excessive distance between pre-K programs and families' homes, hampered by unreliable and costly transportation; (4) lack of adequate facilities making it hard to establish high quality and safe programs; and (5) unavailability of a competent workforce.

\subsubsection{Family poverty}

Numerous studies show an association between family poverty and compromised brain function (Hanson et al., 2013; Luby et al., 2013), and cognitive/developmental outcomes (Atkinson et al., 2015; Jeon et al., 2014). Furthermore, it is not the nature of the povertyrelated risk factors, but the quantity or accumulation of risk that has the greatest impact on children's development (Appleyard, Egeland, van Dulmen, \& Sroufe, 2005; Sameroff, Bartko, Baldwin, Baldwin, \& Seifer, 1998). Psychosocial stress in the context of poverty can directly impact children's brain development and neurological functioning, evidenced by their inability to self-regulate and be goal-directed, which are important cognitive skills (Blair, 2010). 
The negative association between poverty and related factors (e.g., child health, neighborhood safety) and children's outcomes and well-being has been substantiated in rural communities. For example, in the Family Life Project, researchers found familial and social risk factors (i.e., maternal education, family income, two-parent households, employment, job prestige, maternal health, household density, neighborhood safety, and food sufficiency) was consistently and negatively related to children's prosocial behavior, executive function, and language, and this relationship did not vary as a function of child gender, race, state of residence, or degree of geographic isolation (FLP Key Investigators, 2013). That is, the more risk factors children experience, the lower their language, social competence, and executive function skills. The negative impacts of poverty may be particularly amplified in communities with fewer resources, limited access to childcare and preschool programs, and less fiscal support for education (Malik et al., 2018).

\subsubsection{School mobility}

School mobility in rural communities can occur for many reasons. In some cases, rural residents move toward better economic and social opportunities, which could have positive outcomes if it results in better resources and opportunities for learning (Schafft, 2006). Alternatively, rural mobility may not reflect movement to an area of opportunity but rather mobility between low-resourced and distressed communities. Indeed, the latter is likely to be disruptive and have a negative impact on children's learning and well-being. In the case of rural communities, residential mobility could also have detrimental impact on children who remain in schools, as it may negatively affect school administrators' abilities to adequately plan and budget (Schafft, 2005). Vernon-Feagans and Cox (2013) did not find mobility to be associated with rural children's executive function in pre-K and kindergarten. These mixed effects of mobility underscore the need to explore its salience for rural children's educational experiences, especially in light of other familial and social stressors, such as poverty and limited access to services.

\subsection{Mesosystem}

In the present study, we focus on the mesosystem of family engagement that connects children's home and school environments within the rural context.

\subsubsection{Family engagement}

Evidence regarding the important role of family engagement in early learning is clear (Galindo \& Sheldon, 2012). The recent consensus report from the National Academies of Science, Engineering, and Mathematics, Parenting Matters, indicates unequivocally that parents' authentic engagement in their child's learning and schooling in the early years matters for children's academic and social outcomes (National Academies of Sciences, Engineering, and Medicine (NASEM, 2016); however, this report did not speak directly about rural communities. In their systematic review, Semke and Sheridan (2012) note that while there is a need for more research about family engagement in rural settings, several themes were evident. These themes included: the positive relationship between rural familyschool connections and student outcomes, the efficacy of home-school programs on rural student outcomes, the importance of rural school's connection to the entire community, 
and the need for rural schools to address barriers to family engagement. Limited time, distance between home and school, and low-wage and nonstandard jobs have been posited as contributing to low family engagement (Bauch, 2001). High teacher turnover coupled with a high percentage of inexperienced or poorly prepared teachers limits effective and sustained connection between families and teachers (Holmes, Witte, \& Sheridan, 2017), contributing to barriers in family engagement in rural communities. Rural schools, however, have many assets not found in urban schools that may be particularly beneficial for parent engagement and home-school partnership, such as intergenerational connections (e.g., parents and teachers who grew up together) and community cohesion that allows teachers and families to interact outside of school settings (Bauch, 2001).

\subsection{Exosystem}

In the present study, we focus on exosystems, or the social environment that indirectly influences a child's development, such as school and community resources within the rural context.

\subsubsection{School resources}

School resources (per pupil expenditure; teacher education, experience, and salary; and teacher to student ratio) are related to student achievement, with effect sizes large enough to be educationally important (Greenwald, Hedges, \& Laine, 1996; Matsudaira, Hosek, \& Walsh, 2012; Perry \& McConney, 2010). Indeed, school resources and assets are often intermixed with the ability to provide pre-K access and small class sizes. National data indicate that rural communities, especially high-poverty rural communities, often lag behind in per pupil expenditure, teacher education, and teacher salary (Provasnik et al., 2007). In fact, a higher percentage of pre-K teachers in rural communities use public assistance compared to those in large towns and urban areas and live at or below the poverty level (Roberts, Iruka, \& Sarver, 2017). Rural communities are often in need of federal support for early education because children frequently lag behind in school readiness and demonstrate a greater need for special education placement, which increases the cost for educating children (Smith et al., 2008). Greater student needs, coupled with an insufficient tax base, may place an economic stress on schools. This economic stress may create burdens for rural schools to provide high-quality educational experiences and instruction (Monk, 2007).

\subsubsection{Community resources}

Community-level poverty, unemployment, and crime are negatively related to child outcomes, including below-average reading skills in fourth grade, and likelihood of dropping out of college (Chung et al., 2016). A community's poverty alone has been found to be associated with lower test scores for children aged $4-5$ years. Although somewhat attenuated, this association is independent of other socioeconomic indicators (McCulloch \& Joshi, 2001). Rural communities are often characterized by restricted access to childcare, health care, and social services, including mental health services, domestic violence services, and emergency food (Flora, Flora, \& Gasteyer, 2018; Lichter, Parisi, Taquino, \& Beaulieu, 2008). This lack of services is compounded in rural settings where the provision of social services 
is further impacted by distance and stark resources, such as limited public transportation and few skilled practitioners (Miller \& Votruba-Drzal, 2013; Monroe \& Tiller, 2001).

As a way to combat the challenges of living in low-resourced rural communities, attention has focused on community partnership. A strong sense of collective socialization in rural communities is conducive to the development of strong family, school, and community engagement and partnerships, and a potential buffer against the effects of community disadvantage (Bauch, 2001; DeMarco \& Vernon-Feagans, 2013). Thus, there is a need to understand how community partnerships may be particularly relevant for children's early learning experiences.

\subsection{Macrosystem}

In this present study, we focus on the norms, cultural customs, and policies of rural communities.

One unique feature of rural communities is the long-term stability of residents. More recently, however, rural communities are experiencing an influx of racially, ethnically, and linguistically diverse residents (Lichter, 2012). Some studies have noted that the acceptance of ethno-racial, immigrant, and migrant families and their children who may look different and speak a language other than English is difficult due to the close-knit nature of rural communities (Lichter, 2012; Smith \& Krannich, 2000). For these families and their children, the experiences associated with racial and ethnic diversity are confounded by their level of education and poverty level in comparison to natives. Thus, early learning experiences for ethnic minority and non-English-speaking children and their families may be vastly different than their White, English-speaking peers.

\section{Current study}

There is a need to deepen our understanding of the direct and indirect influence of rural children's ecosystems on development, including access to early learning programs (microsystem), family-school connection (mesosystem), school and community resources (exosystem), and community norms (macrosystem). While these issues apply in both urban and rural settings, there is a need to understand more fully how they operate in low-wealth rural communities with distinctive geographic, economic, and demographic realities, especially as many rural states seek to provide pre-K programs to children.

Many systems directly and indirectly affect rural children's development and learning opportunities. Variables within the context of rural communities can either support or hinder children's early learning opportunities, which have implications for their achievement and life outcomes. In this study, we seek to understand the extent to which the rural context shapes how all other ecological systems connect to children's early learning opportunities. Specifically, our research questions are:

1) What aspects of children's ecological contexts shape their early learning opportunities?

2) How does living in a rural community intersect with other ecological contexts to shape children's early learning opportunities? 


\section{Method}

\subsection{Study context}

This study took place in Nebraska. The U.S. Census shows that there are almost 2 million people in Nebraska, and 7\% - or approximately 133,000 children-are under age 5. Over $85 \%$ of Nebraska's 93 counties are rural, with $45 \%$ of children in Nebraska living in nonmetropolitan counties. The Kids Count report (Voices for Children in Nebraska, 2018) indicates that 11 out of 93 counties statewide had no licensed childcare facilities in 2017, and roughly $75 \%$ of counties in Nebraska with child care facilities do not have enough available slots to meet the estimated current demand, which is mostly in rural communities. In addition, pre-K teachers in rural Nebraska are less likely to have a bachelor's degree, more likely to utilize public assistance, and more likely to live at or below the poverty line compared to pre-K teachers in urban Nebraska (Roberts et al., 2017).

\subsection{Study description}

The data for this paper are derived from the [name withheld to ensure study anonymity], a Nebraska-focused study about the learning experiences of pre-K through Grade 3 children in both urban and rural areas. School districts from across the state were identified and recruited into the study based on the following criteria: (a) $40 \%$ or more of students within the district were eligible for free and reduced-price lunch, and (b) the district provided public pre-K services. Within each school district, Title I schools were selected to participate in the study.

\subsection{Subsample for current study}

The subsample for this study focuses on 10 rural Nebraska school districts that were recruited and volunteered to participate in the full study. These rural school districts comprise 15 schools and two Head Start programs run by nonprofit entities. Participating districts had an average of $54 \%$ free and reduced lunch rate (free lunch is based on families with annual incomes at or below $130 \%$ of the federal poverty line; reduced lunch is based on those at or below $185 \%$ of poverty), $17 \%$ mobility rate (determined by dividing the number of highly mobile students [defined as any student who enrolls in two or more public schools during an academic year] by the total number of students within a school or district for a given year), and $4.5 \%$ English language learners $\left(E L L^{2}\right)$, with a range of $0 \%-26.2 \%$ across schools (see Table 1 ).

In the 10 school districts, a total of 101 interviews with 130 participants were conducted. The interviews included school board members, superintendents, principals, pre-K directors and teachers, Kindergarten teachers, and parents (see Table 2). 
IRUKA ET AL., EARLY CHILDHOOD RESEARCH QUARTERLY 52 (2020)

\begin{tabular}{lc}
\hline Table 1. Participant representation across all districts \\
\hline Interview type & Interview count \\
\hline Board Member & 8 \\
Early Childhood Teacher & 18 \\
Head Start (Teacher and/or Supervisor) & 7 \\
Parent & 35 \\
Primary Teacher & 31 \\
Principal & 16 \\
Superintendent & 11 \\
Other (e.g., Student Services Coordinator) & 4 \\
Total & 130 \\
\hline
\end{tabular}

\begin{tabular}{lcc}
\hline \multicolumn{3}{l}{ Table 2. Descriptive statistics of key variables for communities and schools } \\
\hline \multicolumn{1}{l}{ Variables } & Frequency/mean $(S D)$ & Range \\
\hline Community $(N=10)$ & & \\
Poverty Rate $(100 \%$ FPL) & $.86(4.45)$ & $.41-3.83$ \\
Unemployment Rate & $2.2(1.05)$ & $9.05 \%-47.66 \%$ \\
Mobility rate & $16.53 \%$ & \\
School $(N=15)$ & & \\
Pre-K full-day & $36 \%$ & \\
Pre-K half-day & $57 \%$ & $31.97-100$ \\
Pre-K mixed & $7 \%$ & $8.60-47.66$ \\
Free/reduced lunch rate & $54.07 \%(16.86)$ & $0-26.2$ \\
Mobility rate & $17.49(9.61)$ & \\
ELL status & $4.50 \%$ & \\
\hline
\end{tabular}

Note: FPL = Federal Poverty Level, ELL = English language learner

\subsection{Interview procedures}

Interview questions assessed perceptions about ecological factors and explored school policies and practices in six areas: (1) program organization including structure, resources, and transitions across grades; (2) responsiveness including the needs of children and policies related to access; (3) instructional practices including curriculum alignment; (4) use of data including testing and performance standards; (5) community and family partnerships; and (6) innovations and areas for improvement. Interview questions were cognitively tested and revised to ensure comprehension by interview participants (Collins, 2003; Presser et al., 2004); cognitive testing occurred initially with select research staff and subsequently with the full interview team participating in the first site visit to determine areas for enhancing interview protocols.

Information was gathered prior to a site visit for each participating school including community demographic data (e.g., poverty rate, ${ }^{3}$ unemployment rate), school and district policies and practices (e.g., parent engagement practices, school schedule), and school and district data (e.g., free and reduced lunch rate, mobility rate). Site visits with each school in the participating districts were then arranged wherein project team members conducted 
semistructured interviews with participants at each school. Interviews were typically conducted one-on-one, though up to four individuals participated at a time. Each interview lasted approximately $45 \mathrm{~min}$.

\subsection{Data analysis}

Each interview was audio recorded and comprehensive notes were prepared. The notes were uploaded into Atlas.ti@, a qualitative software package. The interviews were initially coded using the constant comparative technique (Glaser \& Strauss, 1967; Lincoln \& Guba, 1985). This resulted in eight major themes that arose from the data (see Table 3). Inductive coding allowed themes to emerge from the data. This inductive coding and thematic analyses process were used to better understand how ecological contexts were described by participants using all data. A coding guide was constructed with a broad definition for each major area that was arrived at in consultation with the research team. There were 99 variables identified in eight code families. Once a codebook was established and agreed upon by all coders, all interviews were coded for the presence or absence of each variable. If a variable was detected, coders extracted the quotation they relied upon as evidence. A total of 25 interviews were coded by all three coders, and the remaining 105 were divided among the three coders to be coded independently. A periodic testing for interrater reliability was used.

Table 3. Rural early childhood themes within the bioecological framework

\begin{tabular}{|c|c|c|}
\hline Theme & Description & Exemplar \\
\hline \multicolumn{3}{|l|}{ Microsystem } \\
\hline $\begin{array}{l}\text { 1. Early childhood classroom en- } \\
\text { vironment: There is limited ac- } \\
\text { cess to quality pre-K programs } \\
\text { in rural Nebraska. }\end{array}$ & $\begin{array}{l}\text { Head Start and school-based pre-K } \\
\text { programs often do not meet the } \\
\text { community demand for quality } \\
\text { preschool in rural communities. } \\
\text { Few other pre-K programs are } \\
\text { available. }\end{array}$ & $\begin{array}{l}\text { There is a waitlist to get into the pre- } \\
\text { school. . . Many middle-income } \\
\text { families and above-income families } \\
\text { are not getting into any program at } \\
\text { all. There are other programs in the } \\
\text { community - like the child develop- } \\
\text { ment center and a couple other pre- } \\
\text { school programs; however, there are } \\
\text { many who end up not getting to get } \\
\text { to go to preschool at all and head } \\
\text { straight to kindergarten. - Early } \\
\text { Childhood Teacher }\end{array}$ \\
\hline $\begin{array}{l}\text { 2. Early childhood classroom en- } \\
\text { vironment: Rural pre-K varies } \\
\text { by length of day (full or half), } \\
\text { though the classroom structures } \\
\text { are very similar. }\end{array}$ & $\begin{array}{l}\text { Schools offer half-, full-, or } \\
\text { mixed-day programs. Pre-K } \\
\text { programs follow the same or } \\
\text { similar curriculum (Creative Cur- } \\
\text { riculum), Teaching Standards } \\
\text { Gold assessment, classroom size } \\
\text { (20), and inclusivity practices. }\end{array}$ & $\begin{array}{l}\text { The curriculum is set up so that the } \\
\text { Creative Curriculum is aligned with } \\
\text { Gold, which is aligned with the early } \\
\text { learning guidelines for Nebraska.- } \\
\text { Early Childhood Teacher }\end{array}$ \\
\hline
\end{tabular}


IRUKA ET AL., EARLY CHILDHOOD RESEARCH QUARTERLY 52 (2020)

Table 3. Continued

\begin{tabular}{|c|c|}
\hline Theme & Description \\
\hline $\begin{array}{l}\text { 3. Family environment: Rural } \\
\text { families struggle with } \underline{\text { low soci- }} \\
\text { oeconomic status and a lack of } \\
\text { resources to address needs. }\end{array}$ & $\begin{array}{l}\text { Poverty rates were high in each of } \\
\text { the school districts. Rural schools } \\
\text { work to support families, connect } \\
\text { them with resources, and help } \\
\text { students experiencing poverty. } \\
\text { Still, many interviewees report } \\
\text { negative impacts on student } \\
\text { learning and social-emotional } \\
\text { well-being. }\end{array}$ \\
\hline
\end{tabular}

4. Family environment: Economic instability leads to high student mobility, which is a challenge for rural schools and impacts student learning.
Mesosystem

5. Family engagement: Family engagement is a priority for rural pre-K programs and important to support early learning.

\section{Exosystem}

6. School resources: Adequacy of school resources varies by school district, but all schools are concerned about the changing and limited availability of funding.

7. Community resources: $\mathrm{Com}-$ munity partnerships are essential to supporting early childhood students in rural schools.

\section{Exemplar}

There are some students with high social-emotional needs because of home experience. There is a high poverty rate in [our town]. Seven years ago, an industry left, and after, much of that population left. The population makeup of [our town] is creating new challenges (e.g., drug issues, poverty, not a lot of opportunity for employment) in (our town].-Principal and ECE Coordinator

Rural student mobility averages $16.83 \%$ but reached $47 \%$ in one school. Rural school mobility is affected by migrant families, proximity to Native American reservations, and split custody. Because students move between districts, consistency in learning is a barrier.

Family engagement in pre- $\mathrm{K}$ is typically high due to required home visits and family engagement policies and practices such as school events, regular communication with families, parentteacher conferences, and policy involvement.

Funding sources are often based on property taxes and state-based funding, which may vary year to year. Schools worry that limited financial resources may negatively impact student learning.

Schools partner with a variety of community agencies to help address the needs of students and their families, including medical and dental agencies, after school care, mental health providers, child welfare agencies, basic needs (food, clothing), juvenile justice agencies (such as probation), and law enforcement.
We started to see a migrant population about 18 years ago, based on the plant. They would come in the spring and stay until the end of October. It was very difficult. Some have stayed here from October to March.

- Principal

We do some coaching of parents on how to work with children at home, like on fine-motor skills such as picking up scissors. I give suggestions on what to work on at home, such as patterning and getting dressed. Most all parents are willing, but it helps to know how. - Early Childhood Teacher

Next year, [we are] expecting a drop in resources available; this fluctuation in resource accessibility is tax funded. - Principal

The community, I feel, really steps up. They raised the funds for the playground. Now they are raising funds for the electronic signs. The community seems involved. All the classrooms are well stocked. The businesses are always tapped for donations.-Parent common in the public sector, being 
Table 3. Continued

\begin{tabular}{lll}
\hline Theme & Description & Exemplar \\
\hline $\begin{array}{l}\text { Macrosystem } \\
\begin{array}{l}\text { 8. Culture: Rural schools are } \\
\text { challenged by changes in de- } \\
\text { mographics and feel highly }\end{array}\end{array}$ & $\begin{array}{l}\text { Because rural communities are } \\
\text { small in population, changes in } \\
\text { demographics can occur quickly, } \\
\text { nity members. }\end{array}$ & $\begin{array}{l}\text { There is a lot of community pride. } \\
\text { People see the value of education } \text { and } \\
\text { are concerned about the drain of } \\
\text { population from rural to urban. }\end{array}$ \\
& $\begin{array}{l}\text { Schools work to address the } \\
\text { changing needs. Rural culture } \\
\text { impacts the school. Schools are } \\
\text { central to community well-being }\end{array}$ & \\
& $\begin{array}{l}\text { and are supported by the larger } \\
\text { community. }\end{array}$ & \\
&
\end{tabular}

Interrater reliability was computed for the presence or absence of coded variables in each interview. Interrater reliability across all 99 coded variables was calculated for approximately $13 \%$ of the interviews. Randolph's free-marginal multirater kappa (Randolph, 2005, 2008; Warrens, 2010) was calculated. Any shift in reliability was addressed through review of coding disagreements and resolution by consensus. We achieved a free-marginal kappa score of greater than .7, which is considered acceptable for interrater agreement.

\section{Results}

In this section, we examine rural Nebraska children's ecological contexts through the lens of the bioecological framework - microsystem, mesosytem, exosystem, and macrosystem (see Fig. 1)-and examine how facets of the bioecological framework are viewed by stakeholders (i.e., parents, teachers, administrators) within rural Nebraska. We present themes that emerge across various respondents and provide quotes to elucidate the themes.

\subsection{Microsystem}

The manner in which rural educators describe children's microsystems is captured categorically as early childhood classroom environments (including curricula used and instructional practices), and family environments/student needs. Microsystemic variables in the early childhood education programs that may influence the learning of rural Nebraska children include access, dosage(length of day), and instruction; those variables in the home environment include family poverty, mobility, and support for learning. Rural Nebraska pre-K programs vary widely in program length, number of students served, and transition practices. Whereas these factors impact children directly, they are often decided in conjunction with demand, time, and federal and statewide policies. For example, Head Start funding strongly encourages classrooms to be full day; non-Head Start programs can be delivered using part- or full-day structures and can be executed over a full (5-day) week or fewer days per week. Nebraska policies for school-based pre-K programs (Title 92, Nebraska Administrative Code, Chapter 11) dictate that students receive a minimum of $12 \mathrm{~h}$ per week and $450 \mathrm{~h}$ per school year. In our sample, three school districts offer half-day early childhood programs, six districts offer full-day programs, and one school district 
offers a mix of full-day and half-day programs. Children are admitted to school-based pre-K programs based on need (e.g., socioeconomic, academic, or developmental), with children experiencing high need or more risk factors given priority.

The perceptions of respondents across the 10 rural Nebraska school districts vis-à-vis relevant microsystem factors (i.e., early childhood programs and family environments) potentially impacting children's learning are summarized below.

\subsection{Early childhood learning opportunities}

Pre-K availability is often limited within rural Nebraska communities. Schools and Head Start programs may be the only community resources for preschool programming (pre-K and preschool are also used interchangeably by interviewees), though faith organizations and home-based childcare programs sometimes offer programs primarily geared for 3and 4-year-olds that adhere to the Department of Education guidelines, such as teacher credential, curriculum and instruction, and structure of learning. Schools that do provide pre-K are often limited in space and resources.

The [school-based pre-K program] is really the only preschool in the area. I think it's crucial in our community to have the early childhood program to help those kids learn.

\section{School Board Member}

Schools often have an application process to gain access to pre- $K$, and enrollment is typically based on need. Many schools have a wait list for the school-based or Head Start programs.

We have dropped the waiting list a long ways, though now it's inching up again. We have one other community pre-K program in a church setting, and the quality of that program has improved, but it's a more expensive option so a lot of families cannot afford it. But at least it's another option.

$$
\text { Early Childhood Teacher }
$$

Students without pre-K often struggle with academic and social skills when they enter Kindergarten. The difference in preparedness of students for Kindergarten can lead to children's difficulty acclimating to a school environment or teaching challenges.

Parents work now and they don't have time to teach kids things like shapes and clothing and building, so preschool has to teach those as well as have kids prepared for the high expectations of Kindergarten.

\section{Kindergarten Teacher}

Once students arrive at preschool, their experience may differ across and within districts. All Head Start classrooms in this study were full-day; however, non-Head Start school programs included part-day or full-day programs, and either full or partial week. Often schools must balance the use of scarce resources to meet community demand for 
pre-K with the need to provide high-quality, play-based academic and social skills education for a smaller number of students:

There is no wait list at the moment, but registration trends indicate that there may be a wait list next year.

Early Childhood Administrator

In rural Nebraska most pre-K programs follow Head Start Program Performance Standards. At the pre-K level, curriculum is often decided by funding source; for example, all Head Start-funded programs have elected to use Creative Curriculum to guide academic and social learning. All pre-K programs in Nebraska are required to use Teaching Strategies Gold developmental assessment practices, so curriculum must align with this mandated assessment tool. Pre-K curricula are aligned with state standards; however, implementation of instructional practices differs by program.

The curriculum is set up so that the Creative Curriculum is aligned with Gold, which is aligned with the early learning guidelines for Nebraska. It all goes hand in hand, so I don't have to struggle with finding and constructing activities that align with the standards.

Early Childhood Teacher

The Creative Curriculum program is more play-based and student-driven than $\mathrm{K}-3$ curricula. Rural Nebraska pre-K teachers work to address developmentally appropriate learning while meeting various needs and developmental stages of pre-K students. Some educators indicated the Creative Curriculum program could be onerous to teachers and children because multiple weeks are dedicated to a single topic, and some teachers suggested the curriculum is not play-based enough.

In rural schools, the transition process between pre-K and Kindergarten can be formal, informal, or minimal. Some schools regularly host a "Kindergarten round-up" to assist with transition, inviting pre-K students and families to Kindergarten classrooms to meet their teachers-to-be and learn about expectations. Pre-K program staff in rural Nebraska often work closely with Kindergarten teachers to prepare students both academically and socially for Kindergarten by having meetings to discuss the academic expectations of Kindergarten. At the same time, pre-K programs use a different curriculum than is used in Kindergarten through Grade 6, so pre-K to Kindergarten alignment can be a challenge for schools. For some pre-K programs, the dispersion of children to multiple Kindergartens in the school district can be a barrier to effective transitions:

For the transition, some preschoolers stay, and some go to other schools. For the ones who stay, that transition is easiest to transition with the teachers already in the building - we communicate about what has worked and what hasn't. The kids that are going to other schools - we have less communication.

Pre-K Coordinator 
In some schools the sharing of information between pre-K and Kindergarten is less formal, even when classrooms and teachers are in the same building, as attested by Pre-K Teachers: The Kindergarten teachers and preschool teacher mostly just talk to each other about students; there is no formal way of passing along data on them. In other schools, there is very little transition planning between pre-K and Kindergarten: There is not a lot of information sharing between preschool teacher and Kindergarten teacher unless there are concerns about a certain student.

Educators in our study indicated that social-emotional instruction and behavioral programs begin during pre-K. Many pre-K classrooms in rural Nebraska schools reported using the Second Step program to promote social-emotional learning. This program is either used schoolwide or in pre-K classrooms only. In pre-K programs using the curriculum, parents receive notification about the program so they can implement activities to support the curriculum at home. Pre-K teachers believe that preparing students' social-emotional development is key for Kindergarten success.

The focus on social-emotional skills is huge, rather than just pre-academics. So things like how to ask a friend to play and how to be safe and respectful and responsible. We have those three expectations everywhere. We want them to learn that there are rules to follow.

Early Childhood Teacher

In addition, many schools use a schoolwide behavior program, Positive Behavioral Interventions and Supports (PBIS), which is also referred to as "Pyramid," given its tiered approach to behavior management. Schools that utilize PBIS often implement it at the early childhood level and integrate a parent advisory group as part of its implementation.

\subsection{Family environment and student needs}

Educators discussed a number of factors within students' home lives that present challenges for effective education. A theme prevalent in rural communities pertains to needs associated with families experiencing low socioeconomic status. High rates of poverty and low-income families were noted in many participating schools and their surrounding communities; in many of the school districts, poverty rates were perceived as increasing in recent years (data from Nebraska Kids Count shows a small increase in poverty from $11.2 \%$ in 2007 to 11.4\% in 2016). Basic needs such as clothing, affordable transportation, food, employment, and housing were mentioned as needs for many families. As indicated by one rural principal: Many of the kids' parents do not have good jobs, if jobs at all. Therefore, it becomes a cycle of poverty and no place for these people to go. Some of these families have nothing.

Educators discussed student mobility as a barrier to learning. Students missing significant parts of the school year or switching schools was identified as an educational challenge. This is particularly relevant given the extensive research demonstrating connections between attendance and early childhood outcomes (e.g., Attendanceworks.com; Dubay \& Holla, 2015; Ehrlich, Gwynne, Pareja, \& Allensworth, 2014). There are a variety of reasons for high mobility in rural areas, including close proximity to Native American reservations with children moving between the reservation and the school community, children who have parents who live in different communities and whose time is split between parents, 
schools in communities with high concentrations of migrant workers who spend only part of the year in the school district, and high populations of first-generation Mexican and Central American children who visit family in their country of origin for extended periods.

Probably half of the students in our district are Hispanic. Many of those parents do not get to pick their vacation days - so whenever they can, they go back to their home country. Having students leave for long periods of time during the school year is very hard to catch them back up.

\section{Principal}

In addition to attendance issues related to mobility, participants discussed other issues with attendance as a barrier to learning. In some jurisdictions, tardiness was considered a larger problem than school absence. Educators noted a variety of potential contributors to attendance issues, including lack of transportation and parental factors, such as working multiple jobs. For students in Kindergarten through third grade, schools employ a number of strategies to ensure attendance, including use of a truancy officer; however, since attendance is not mandated in pre- $K$, schools use different approaches to encourage parents to get their children to school. A local Head Start Program Director explained their process:

We have a new standard with attendance because of the correlation between attendance and performance. If the child is not going to be at school, then parents need to call within an hour of the school day. If not, we will reach out to you during the day. If we cannot get into contact with you on the second day, we will reach out to the emergency contact listed. On the third day of absence and no contact, there will be a letter and home visit.

Another aspect of family environment that challenges learning relates to parenting needs. In addition to parenting challenges related to poverty and low income, educators expressed families have other challenges including mental health needs, substance use issues, abuse and neglect issues, domestic relationship issues, traumatic experiences within the home, and lack of understanding of how to support the educational needs of their children, either in preparing them before they enter school or in supporting education gains from school. An example was provided by a school Principal and Early Childhood Coordinator: It's a problem that kids come to school not ready to learn. For example, there was an incident in the fall where kids were removed from the home because of drugs and weapons. That's hard for kids to learn or even want to learn-so we worry about how to reach those kids.

Educators discussed behavioral issues of children coming to school as a concern related to learning. Often behavioral issues were attributed to other challenges, such as poverty, parental drug use, domestic abuse in the home, and lack of parenting skills.

The biggest struggle day to day is the defiance with some of these kids. If I had a magic wand it would be to help the support structure in some of these families.

Early Childhood Educator 
Language barriers were another issue confronting schools, although generally educators thought they had adequate resources to address these needs. In addition to students, schools have challenges in communicating with caregivers who may not speak English. Schools varied in the proportion of students who required assistance with English.

About $10 \%$ of our student population is learning English as a second language, and we have seen more of a spike. Some of them not only do not speak English but may not have even gone to school in their own language. That is more of a challenge.

Superintendent

\subsection{Mesosystem}

The mesosystem interactions are those where the immediate environments interact, such as through family engagement with schools and Head Start programs. Nebraska policy (Title 92, Nebraska Administrative Code, Rule 11) requires the inclusion of early childhood education standards related to family development and support. Specifically, the policy mandates at least two home visits per year and written information for families, both of which should include services to enhance parenting skills and access to community services (\$005.02 A-E). Both Nebraska and Head Start policy (§1304.41(b)) mandate the creation of advisory committees that include parents. The advisory committee is intended to ensure community participation in the early childhood education decision-making process.

Many respondents identified the role of parents and families as a critical topic, linking it to children's learning. Thus, family engagement (including communication with families, home visits and conferences, and support for learning at home) is considered an overarching theme within the level of the mesosystem.

\subsubsection{Family engagement}

Participants in the study discussed a number of issues related to family engagement in school activities and their children's learning. Pre-K teachers indicated they used a variety of strategies to communicate with parents and other caregivers. Often these communications are informal, as when parents dropped off or picked up their children from school.

Good communication with parents on both academics and behaviors builds consistency between home and school.

Early Childhood Teacher

Pre-K teachers use a variety of formal communication approaches with families. Some of the strategies they use include sending home a regular newsletter to inform families about what is occurring in the classroom, sending home a folder with the child to inform parents about what they have been working on in class, and using social media (e.g., Facebook, Twitter) to interact with parents about general classroom activities. Teachers also call, email, and text parents to inform parents about concerns such as problem behaviors, and to provide specific information about a child. Home visits are also part of engaging with families, per Nebraska requirements. 
Participants discussed the variety of activities they engage in with families during the home visits, including working with parents to teach them the skills they need to support their child's learning, developing goals and communicating expectations at the beginning of the year, reviewing how the child progressed at the end of the year, sharing results from assessments, and soliciting information to better understand family culture.

Parent-teacher conferences are another method for engaging parents. Generally, in addition to home visits, schools conduct two parent-teacher conferences per year, which are used to build strong relationships with families, communicate expectations, describe strategies for parental support of learning, and provide information about student progress. Most educators indicated that participation in parent-teacher conferences and home visits was high, but some noted barriers such as the busy schedule of parents who maybe farming/ranching or working multiple jobs, transportation challenges for some families, and with regard to home visits, reluctance to let educators into their homes.

A common theme across schools was that parents were satisified with the communication methods used by teachers and schools:

We get a lot of communication. Every Sunday night, there is a call to the whole school. It is a rundown of the week and reminders. I probably get an email once or twice a week from the district about what's going on. There are Facebook pages for classroom, school, and district.

Parent

The teacher will call after school using her own time; I appreciate getting that communication rather than just a note.

Parent

Educators discussed the variety of ways they engage parents in helping their children learn and develop: We do some coaching of parents on how to work with children at home. I give suggestions on what to work on at home, such as patterning and getting dressed. Most all parents are willing, but it helps to know how. An early childhood director discussed more formal arrangements with parents: We do a compact with parents, looking at what parents and teachers can do independently and together to help students and signing off on it.

Some educators discussed efforts to provide education to parents as a form of family engagement. For example, some schools have ELL classes for parents and specific programs for certain populations:

We have a migrant program. The state sends us a migrant recruiter, and we give them demographic information. She is a native speaker and goes around and finds those families that are migrants. She gives support to those families and to the school if the families will sign. That migrant recruiter also becomes a tutor for those kids, and there are migrant meetings with parents. And they continue some education through the summer.

Early Childhood Education Director 
Generally, educators indicated that school events are well attended by families, including movie nights, carnivals, and clubs or activities involving both children and parents. Participants discussed having parents in the classroom helping with class activities but expressed mixed success in enticing parents to volunteer. Educators identified other ways they engage families, such as parenting classes or special meetings for fathers, mothers, or grandparents.

We've also talked about doing class nights for parents more regularly, about things like health, bedtime routines, nutrition; and we're going to survey parents to see what they think would be helpful.

Early Childhood Teacher

Participants discussed having Parent Teacher Associations/Organizations (PTAs or PTOs) in their schools as well as other organizations such as advisory committees that include parent participation. These groups raise funds to address school needs, hold special events of interest to families, and provide guidance to schools. Not all schools in the study have active PTAs or PTOs. Barriers to parent participation in forming active organizations include lack of time by parents, difficulty engaging parents from low socioeconomic families, and challenges attracting younger parents.

Schools had varying experiences in engaging parents in policy development. Mechanisms for engaging caregivers in school decisions include allowing input to school boards, having an open-door to superintendents and principals, involving parents in strategic planning processes, and conducting surveys of parent opinions regarding potential policy changes. Some schools have taken an active approach:

We are in the process of coming up with a strategic plan as a board. It includes focus groups, and we have somebody from the Nebraska State School Board Association that is helping us do the strategic plans. They are going to help us recruit and conduct those meetings. It is an opportunity for parents and businesspeople to come in and voice what they want our school to be doing for the children who go through.

School Board Member

Other schools have taken a more passive approach to parent engagement in policy development:

We do not have a PTO. Parents are really not involved in policies or anything of the sort. They are welcome to come to the School Board if they want to, but I have never seen that happen.

Principal

\subsection{Exosystem}

Exosystem influences are those that are external to the immediate environment but nevertheless impact student development. Our study is concerned with rural exosystems; herein we explore specific rural community factors such as demographics, school resources, and 
community resources. The average student population in the 10 rural districts in the present study was $2498.72(S D=1931.09)$ with a range of 308 to 5898 students. The average population of the district catchment areas was 15,975.07 (range $=2104$ to 36,232 ). For rural school districts included in this study, $12.64 \%$ of families with children under the age of 5 were below $100 \%$ of poverty (maximum of $26.5 \%$ ), much higher than poverty rates for all families/individuals in the communities (8.86\%). Districts reported an average of $54 \%$ free and reduced lunch rate (defined by $130 \%$ poverty). At the same time, unemployment rates were low $(2.2 \%$; range $=.4 \%$ and $3.8 \%)$, suggesting issues related to low-paying jobs and lack of full-time employment in these communities.

\subsubsection{School resources}

The type and availability of resources varies widely across rural Nebraska schools and districts. There was a general theme that financially, rural school districts may not be able to depend on a consistent amount of state-supported funding, or that the amount of available funding changed every year. Interviewees expressed concern that financial resources are not sufficient in some areas, particularly when serving high-risk families. Some school districts and buildings have maintained adequate resources despite these challenges, whereas others have struggled. Several principals and educators indicated that they felt financial resources would continue to decline, whereas needs would persist or increase.

Tax-based funding was cause for concern, particularly with property tax adjustments as a political topic receiving quite a bit of news at the time of our interviews.

We are a non-equalized district, so all of our money is coming from taxpayers. We are surviving, but we have to be very smart in how we are spending money. I think we support the teachers well, though.

Principal

A major priority is having sufficient resources to compensate effective teachers to meet the needs of pre-K students. A particular challenge to adequate staffing occurs when classrooms have large numbers of students with high needs (e.g., language, behavior) or students receiving special education services:

We have two sections of 4-year-old preschool. Our limit is 20 per section, but ... we have a number of kids who come to us with no English, we have a number of high-needs students, so 20, even with two paras [paraprofessionals] is more than we want to tackle for the good of the kids we are serving, so we have maxed out at 17 per section.

Superintendent

In addition to financial limitations within schools or districts, rural schools may specifically lack personnel with training to address behavioral needs. Larger or less remote rural communities may have access to sufficient behavioral health or other human resources for specialized needs, but many educators and administrators indicated that very small or distal rural communities often lacked these resources. Lack of sufficient pay or benefits can be a challenge to recruit and maintain qualified personnel. Across several rural districts, 
administrators noted that paraprofessional help was crucial in early childhood classrooms, but it was difficult to retain paraprofessionals because of low pay:

Where we really lack is in the paraprofessional end of it. The pay is not adequate. The labor market has become really tight.

$$
\text { Principal }
$$

Interviewees indicated that the classroom ratios of adults to children vary over time, with changes often occurring in the middle of the school year because of mobility. Teachers indicated that classroom ratios are of a manageable size with sufficient help from support teachers, though more qualified teaching staff or resources to increase sections would be helpful:

I really like a lot of what we are doing, but right now I think our classroom teachers are pretty overworked. We have large class sizes, and we don't have much time to work on paperwork that is required outside of the classroom, so I have been advocating about adding another half-day classroom or something so that our numbers are not quite so high.

Early Childhood Teacher

Many educators indicated that resources for training and professional development are available. However, interviewees also indicated that there were several factors that limited access to such opportunities. Key barriers include lack of district or building funding, or lack of time to participate in training opportunities because of teaching duties-particularly if training activities require travel time to other communities:

That has been tricky. I am kind of on an island, as I am the only preschool teacher... . As far as professional development goes, that is all I have. When I have attended professional development, it requires traveling to [larger cities]. It's a whole day of training and travel.

\section{Early Childhood Teacher}

A number of administrators and educators noted the importance of rural schools actively engaging with regional Educational Service Units (ESUs) for training and support assistance. ESUs in Nebraska can thus serve an important role for rural school districts that are short on personnel or expertise of their own. Other times, the only options for professional development are online:

We have [an ESU] here... . They will send out information on any workshops coming through. They partner with us on different leadership opportunities that they may be bringing in. The district does get certain discounts on professional development through them. I have had people from ESU come into our building to have workshops just for my staff.

$$
\text { Principal }
$$


A number of interviewees indicated they believe their districts and/or buildings had reached maximum capacity for serving students. Oftentimes, classroom size and the number of class sections across grades depends upon building capacity. Administrators and educators indicated that in some rural communities, funds are lacking to expand facilities:

We are squeezed with facilities. My first year here we had nobody sharing spaces. Now it's tight. We are at capacity. The enrollment keeps growing. So many communities are dwindling, but it's not the same here.

\section{Principal}

Many interviewees indicated that pre-K classrooms have adequate technological resources in their classrooms and districts or are in the process of upgrading to new equipment and resources. For example, buildings had acquired and provided tablets, Chromebooks, and software to teachers and sometimes students.

\subsubsection{Community resources}

For Nebraska schools, community partnerships are important resources to combat against disadvantage and support children's early learning. One of the key partnerships occurs between Nebraska school districts and Head Start Programs. Some schools operate Head Start programs directly; in other schools, Head Start is operated by a separate entity such as a community action agency. Relationships between school-based pre-K programs and external Head Start agencies vary by school district. Some schools have very close ties to external Head Start Programs and even co-locate classrooms, while others have a more distant relationship:

Our preschool is in collaboration with Head Start. We are actually located in the Head Start building. We have the same process of admitting students based off of low income as Head Start.

Early Childhood Teacher

In the beginning we talked with Head Start, but they have had so much turnover in staff, so that has not happened.

Early Childhood Teacher

Some schools have relationships with other pre-K programs, such as childcare centers, to help with transition to Kindergarten and to help improve or align curricula with schoolbased pre-K programs. In other schools there was little collaboration with other early childhood programs:

The Head Start closed a 3-4-year-old program. To compensate, we held our first all-community preschool meeting and met with the churches to try to make sure that everyone who wants preschool can have an option in town. It was a great discussion.

School Superintendent 
Little collaboration between schools and other early childhood programs operating in the community was evident in some cases. A number of educators noted differences in quality between school-based programs and other pre-K programs operating in the community:

We would like to see more of a connection between the community preschools and the district. I am seeing more and more kids coming from in-home daycares. I think parents don't always see the importance of the structure. Often, we see parents not realizing their kids are behind coming into Kindergarten.

\section{Primary School Teacher}

Rural Nebraska schools discussed different types of partnerships they have with community organizations. One of the most common partnerships is around afterschool programs. These programs offer help with homework for older children and recreational and educational activities for all children, including participation in clubs such as gardening, reading groups, and 4-H. As stated by one parent, My daughter gets homework help, physical exercise, a snack, and various clubs. She has excelled in the program. In some schools, however, the afterschool program is available for students in Kindergarten and above, but not for pre-K children.

In some schools, before-school and/or summer programs are also offered. These programs are operated by a number of different types of organizations, including university extension, Community Action Agencies, and partnerships with local colleges. Some of the afterschool programs operate as community learning centers (CLCs). Often the afterschool program is free for children eligible for free and reduced lunch services and on a sliding scale fee for others. In some districts, the afterschool program cannot accommodate all demand, and there is a waiting list to participate.

Another common partnership with community agencies pertains to economic assistance for families in need, including food programs. Often this includes providing free meals and snacks for eligible children, food baskets or backpack programs in which backpacks are filled with food, free food at a food market, holiday meals for families, and linkages with local Women, Infants, and Children (WIC) and food pantry programs. Other community-level economic assistance programs include clothing programs such as coat drives, partnerships with libraries to provide books for children to keep, shelters for families who are homeless or needing a safe place, community resources to help families pay utilities and other bills, and linkages to employment and housing services.

We get together with an administrative team from other schools and talk about families and what their needs are. For example, with one family we learned that they were a foster family and had a problem with attendance; I realized she qualified with busing, so we got them busing, and then attendance vastly improved. We had a family who had fleas. We contacted a church and the community rallied around them.

School Principal \& Early Childhood Director 
Schools also partner with a variety of community agencies to help address additional service needs of students and their families, including medical and dental agencies, mental health providers, child welfare agencies, juvenile justice agencies (such as probation departments), and law enforcement. Many schools engage community businesses and philanthropic organizations to help finance a variety of resources within the school.

The community, I feel, really steps up. They raised the funds for the playground. Now they are raising funds for the electronic signs. The community seems involved. All the classrooms are well stocked. The businesses are always tapped for donations.

Parent

Some communities benefit if they have close access to partners like colleges or universities, though that may be rare in remote parts of the state. More generally, early childhood classrooms and school buildings welcome volunteer help from the community, particularly from parents. Parent support groups often assist with small fundraisers for classroom supplies. It is not uncommon for teachers to spend money out of pocket for classroom supplies:

We do have a preschool budget. Right now, our budget is spent. Therefore, I am spending my own money right now. We have done fundraisers in the past.

Early Childhood Teacher

\subsection{Macrosystem}

The macrosystem is inclusive of cultures, norms, and policies within a community or area. In this case, macrosystemic factors include the rural culture and norms that influence child development. For rural early childhood education, the rural context helps to shape both the policies, in terms of demand and access to early childhood, and the experience.

Interviewees considered it important to integrate culture and customs into the classroom experience because of the impact of culture on the larger community. Rural communities may experience rapid changes in demographics and culture because of their small size and frequent changes to industries within their communities. Participants noted the diversity of cultures within the community and need to address the unique cultural needs of families. Some rural schools commented on their interaction with nearby tribal reservations.

There are many cultures represented in schools. We had training in the district on poverty and cultures. It's an interesting area because of the reservation [nearby]. Nearly everyone in the school is Native American to an extent, but there is a distinct line that is drawn with Us and Them. It's On versus Off the reservation. That has been hard as a leader to see that, so it doesn't matter if they are bringing in representatives from the tribe like the dancers. It's harder to bridge that divide because it is within the Native American community.

Principal 
Other schools have growing diversity because of an influx of refugees, immigrant $/ \mathrm{mi}-$ grant communities, or industry. Schools work to integrate English language learning (ELL) programs and migrant programs (such as those that include an early start for migrant workers) to meet the changing needs of students.

We have growing minority populations here-there is a pretty large Hispanic population, and some have limited English. There is a new African American population and Burmese children that have moved in primarily because of [a nearby] packing plant, and they don't have enough housing [there].

Principal and Early Childhood Coordinator

Some schools noted cultural challenges because of the rural nature of districts.

We have a lot of ranch kids, kids who do not have a lot of perspective or opportunities. We have exposed them to a lot of things-even thinking about possible careers-dream and be what you want!

Principal

Most often, participants from rural Nebraska schools felt a strong culture of support and school engagement that is part of the rural experience. Interviewees discussed the strong partnerships they have with community agencies.

There is a lot of community pride. People see the value of education and are concerned about the drain of population from rural to urban.

School Superintendent

Some rural schools noted the success they have had in passing bond issues and securing community support in ensuring adequate financial resources.

The city council just approved another facility for a childcare center, and preschool will be a component of that. The community is really trying to address the demand for quality early childhood education.

School Board Member

Some rural Nebraska school districts work to build on the sense of community in generating support for the school. Others, how-ever, noted the struggle supporting schools.

Property taxes are always a hot topic, especially with the agricultural community. We have a lot of untaxed land, and therefore there is less money for the community. We have been discussing that we reach about 30 percent of the community-mostly people who have a kid or grandchild who attends here. About 70 percent we feel like we don't reach. Those people need to better understand that they have a role in this, in creating a better educated community.

School Board Member 


\section{Discussion}

The goals of this study were to identify the ecological contexts that shape rural children's learning opportunities and to understand how the rural context influences these contexts in shaping children's early learning opportunities. Perspectives were elicited from a diversity of lenses, ranging from teachers and principals to parents and board members. Participants provided insight into how children's ecological contexts support or hinder learning and development. The results highlight the diversity in rural children's ecological systems, including variations in family income, community-level poverty, family engagement, and accessibility of resources for pre-K programs. Educators raised concerns about children's long-term outcomes, especially for children from challenging circumstances such as lowincome households and non-English-speaking migrant families. In general, the manner in which various systems influence one another and subsequently impact children's early childhood opportunities and learning outcomes within the rural context are revealed. Below we discuss each aspect of children's ecological systems and policy implications; policy implications are also presented in Table 4.

Table 4. Rural early childhood themes and policy implications

\begin{tabular}{|c|c|}
\hline Theme & Policy implication \\
\hline \multicolumn{2}{|l|}{ Microsystem } \\
\hline $\begin{array}{l}\text { 1. Early childhood classroom environment: There is } \\
\text { limited access to quality pre-K programs in rural } \\
\text { Nebraska. }\end{array}$ & $\begin{array}{l}\text { Increase public investments in pre-K to ensure } \\
\text { family and child access which can occur through } \\
\text { state school funding formula and expanding access } \\
\text { through increased federal and state investments in } \\
\text { the Child Care and Development Block Grant } \\
\text { (CCDBG) and Head Start programs. }\end{array}$ \\
\hline $\begin{array}{l}\text { 2. Early childhood classroom environment: Rural } \\
\text { pre-K varies by length of day (full or half), though } \\
\text { the classroom structures are very similar. }\end{array}$ & $\begin{array}{l}\text { Provide more resources for schools and community- } \\
\text { based providers to offer full-day programming } \\
\text { along with wraparound services, such as through } \\
\text { the Child Care and Development Block Grant, the } \\
\text { Rural Education Achievement Program, and Title V } \\
\text { grants; provide grants to ensure full-day high-quality } \\
\text { standards are maintained through a mixed-delivery } \\
\text { system such as offering funds for more educators } \\
\text { and coaching support to guide individualized } \\
\text { practices. }\end{array}$ \\
\hline $\begin{array}{l}\text { 3. Family environment: Rural families struggle } \\
\text { with low socioeconomic status and a lack of re- } \\
\text { sources to address needs. }\end{array}$ & $\begin{array}{l}\text { Support families getting higher education and livable } \\
\text { wages, improving their economic self-sufficiency } \\
\text { such as through free college tuition and incentiviz- } \\
\text { ing employers and business to pay higher wages } \\
\text { and offer affordable health care, providing access to } \\
\text { needed mental health for themselves and their } \\
\text { children. }\end{array}$ \\
\hline
\end{tabular}


IRUKA ET AL., EARLY CHILDHOOD RESEARCH QUARTERLY 52 (2020)

Table 4. Continued

\begin{tabular}{ll}
\hline Theme & Policy implication \\
\hline 4. Family environment: The economic instability & Support the economic self-sufficiency of families to \\
leads high student mobility, which is a challenge & live in safe, affordable, and stable housing through \\
for rural schools, which impacts student learn- & federal and local housing grants and initiatives; and \\
ing. & create procedures and supports for children to \\
& remain in same program when move, such as \\
& addressing transportation and development of \\
& Transition Teams for children who move programs \\
& mid-year.
\end{tabular}

Mesosystem

5. Family engagement: Family engagement is a

Continue to strengthen family engagement and priority for rural pre-K programs, and important to support early learning.

foster home-school partnerships and positive parent-teacher relationship through supports to schools and teachers through Title I funds by offering, for example, professional development, coaching for teachers and schools, and home visiting guidelines to effectively engage with families, and coaching and educational supports for parents to engage with teachers and schools.

Exosystem

6. School resources: Adequacy of school resources varies by school district, but all schools are concerned about the changing and limited availability of funding.

Ensure federal and state funding competition consider the needs of low-resourced rural schools; increase funding for infrastructure that addresses facility improvement, licensing and monitoring, and the diverse needs of the workforce, including adequate and equitable pay across settings providing pre-K services.

7. Community resources: Community partnerships are essential to supporting early childhood students in rural schools.

Provide incentives and funds to support communitywide partnerships that leverage and braid funding from multiple sources (e.g., school district, Head Start, CCDBG) to support the learning and developmental needs of children and adequately support the workforce.

Macrosystem

8. Culture: Rural schools are challenged by changes in demographics and feel highly supported by rural community members.

View pre-K as part of a high-quality school system that will help incentivize diverse families to move into and stay in rural communities; create an economic development plan that views pre-K as central to the future workforce and stability of the community.

Note: $\mathrm{CCDBG}=$ Child Care and Development Block Grant

\subsection{Microsystem}

This study confirms the extant literature highlighting the limited opportunities for highquality early learning experiences within rural communities and the need to integrate different options to meet the needs of the community. To ensure that children have some level of early learning experiences, some communities offer part-time programs to serve more children. Preference for state or locally funded pre-K program enrollment are given to children from households experiencing greater levels of risk (e.g., poverty, low education, 
non-English-speaking). Thus, there appears to be a lack of affordable and quality programs for middle-income families, which has implications for children's Kindergarten readiness. This means that children may attend substandard early childhood programs, which have been found to be detrimental to children's outcomes (Vandell et al., 2010). Nevertheless, many school districts balance the use of scarce resources to meet community demand for pre-K, which may include offering pre-K programs in nontraditional settings, such as home-based programs and faith-based organizations. However, this calls for greater public investment in affordable high-quality early learning opportunities, especially in communities with limited options to offer full-day programs (see Table 4).

The diversity of socio-demographic risk factors, including children from mobile, lowincome, non-English-speaking, and migrant households, as well as children from households dealing with substance abuse and mental health issues, emphasizes the challenges faced in many communities. The impact of these issues is amplified in rural districts where resources may be limited in number and difficult to access. Educators noted how the combined factors of poverty and drug use in some homes could have a detrimental effect on children's learning because of the absence of a responsive and caring adult in the home and tenuous housing options, an observation that is consistent with the literature (Jimenez, Wade, Lin, Morrow, \& Reichman, 2016). This calls for the need to identify resources to address both children's early learning and development needs and families' economic selfsufficiency and well-being, to ensure adequate access to mental health services and safe and affordable housing. Recent studies on two-generation models have shown the benefits on children's outcomes and achievement when supporting families' economic self-sufficiency through provision of high-quality early learning (Annie E. Casey Foundation, 2013; NASEM, 2016).

\subsection{Mesosystem}

Results indicated a strong relationship between families and schools in rural Nebraska settings. In particular, educators recognize the value of a strong home-school partnership for children's learning and behavior, consistent with the literature. They utilize different approaches to engage and work with families, including home visits, parent-teacher conferences, and social media. Some schools offer special outreach to groups of families that may need additional supports, such as non-English-speaking families. These efforts are consistent with national studies that indicate that strong home-school partnerships require consistent and varied strategies that meet the needs of the diversity of families in schools and programs (National Academies of Sciences, Engineering, and Medicine (NASEM, 2016). Families interviewed reported the ease with which they can communicate with teachers and their satisfaction with the level of information they received. To further support children, schools sought to ensure seamless transition for children (and their families) from pre-K to Kindergarten. Schools engaged in formal and informal mechanisms of connecting families and children with their new schools and teachers, responding both to the needs of children and their families and availability of time for teachers. These findings support the need to provide resources to support high implementation of strengths- and evidence-based practices that foster home-school partnerships and positive parent-teacher relationship, thereby strengthening family engagement. 


\subsection{Exosystem}

Findings reveal the need for economic support to provide more children with access to pre-K and ensure stability of and support for rural Nebraska Pre-K program staff. This need is often compounded when the policies for funding early learning programs differ at the federal versus state levels, such as the preference for Head Start to be full-time (all Head Start programs in the study sample were full-time) when rural schools can offer only part-time slots. There are significant challenges to providing full-time pre-K programs to all eligible children in need. Rural communities too often have limited resources and are unable to provide a range of reliable and affordable services, including transportation and wraparound services.

More resources are also needed to support children with greater needs, including nonEnglish speakers, children with behavioral challenges, and special education services. Funding constraints have implications for programs' abilities to address the diverse needs of children and families as well as the supports that can be provided. Lack of funding also affects schools' and programs' abilities to expand to serve more children. Likewise, when limited funds yield fewer teachers and larger class sizes, added stress to teach, assess, and support greater numbers of students during these critical years is often the result. Research has documented the impact of stress on teacher quality and retention (Curry \& O'Brien, 2012; Hall-Kenyon, Bullough, MacKay, \& Marshall, 2014). Likewise, the composition of a classroom, particularly the presence of many children with high needs, is associated with teachers' reported depression and stress (Friedman-Krauss, Raver, Morris, \& Jones, 2014). Educators noted the need for potentially reducing class sizes, especially to deal with children with unique or special needs. Thus, there is a need for investment in ensuring access, monitoring, facility improvement, and workforce support to meet the diverse needs of children in rural communities. This investment requires incentives for community-wide support and collaboration to braid funding and share services across various early childhood and family support agencies and organizations.

\subsection{Macrosystem}

Educators recognized that while there is some stability in the way rural communities function, they are also prone to feeling the impact of small changes. Several rural Nebraska communities reported unexpected increases in diversity, including greater numbers of non-English-speaking and refugee families and low-income households. This growth is supported by the Nebraska Kids Count data showing an increase in children eligible for free and reduced-price lunch, from $34 \%$ in the 2005-06 school year to $46 \%$ in the $2016-17$ school year across the state; in addition, the rate of ELLs across the state increased from $6.5 \%$ in $2006-07$ to $7.3 \%$ in 2016-17 school year (Voices for Children in Nebraska, 2018). Due to small community size, increases in the diversity of families present in small rural Nebraska communities are noticeable and require different supports and training as schools adjust to and meet the needs of a more heterogeneous population. For example, rural communities may not have the culturally and linguistically diverse workforce to meet the needs of a changing student population, which has implications for children's early learning experience. Nevertheless, educators noted the level of partnership with communities, especially with an intentional focus on supporting the diversity of children 
with various needs as early as possible. Schools should leverage community resources (e.g., human and social service organizations, community leaders, language supports, or home visiting), perhaps through policies that incentivize innovative partnerships across multiple sectors in rural communities to support children's learning and developmental needs.

Whereas some children in our study are living in poor households and communities and attending low-income and poorly resourced schools, many are living in communities with low levels of poverty and unemployment rates. Also noted was a large variation in the number of non-English-speaking children across rural communities. While school staff emphasized and focused on children from disadvantaged homes and communities, the census data indicated that there was minimal poverty in the communities; however, this discrepancy may be an indication that children(and their families) in public schools, specifically Title I schools, may have more economic and social needs than the children and families in the larger communities. Thus, policies should attend to leveraging the resources in high-resourced communities to support schools with predominantly children from lowincome families. Simultaneously, future economic development plans that view pre-K as central to the future workforce and stability of the community are needed.

\subsection{Implications}

This study provides support for the hypothesis that children's ecological systems are likely to matter for their early learning opportunities. In particular, this study provides insights from diverse groups about the value of pre-K programs for children, families, and communities, and the need for part-time options to accommodate the many children and families that want them. These insights speak to the need for more diverse and adequate funding streams to ensure that children have access to high quality pre-K (preferably fullday learning opportunities) and that teachers are supported to provide the best learning opportunities for children. While the communities within which schools were located did not have high poverty rates, this was not necessarily the case in the school buildings themselves. In such circumstances, rural schools provide an important resource for economically disadvantaged families and their children. There may be a need to ensure that schools in rural communities, regardless of the poverty rates, have resources to support children from low-income households. Even with the challenges of limited availability of full-time pre-K programs and children experiencing economic disadvantage, schools were seeking ways to support families. For example, they purposefully engaged with families and other community agencies such as Head Start, health centers, and mental health providers. As the demographic composition of rural communities changes to one that is more ethnically, culturally, fiscally, and linguistically diverse, there is a need to be proactive to ensure that policies and practices are aligned with the needs of residents. For example, there is a need to ensure a culturally and linguistically diverse workforce as well as curricula and practices that are aligned with changing demographics.

\subsection{Limitations}

This study provides in-depth information about the ecological contexts of rural children; however, it may not generalize to other rural areas. Specific questions focused on early 
learning and education opportunities in rural Nebraska, limiting our ability to examine other issues that may impact children's learning and development, such as housing and transportation as well as children's experiences prior to pre-K. It is critical to examine children's early learning experience through the birth-to-age-five continuum.

Due to time and resources, we interviewed specified individuals and were not able to obtain perspectives of others (e.g., community leaders). Furthermore, our study intended to provide a one-time snapshot of children in rural Nebraska communities who are in centerbased Head Start pre-K programs, school-based pre-K programs, and Title I schools; thus, it cannot be generalized to children in home-based settings, parent-only care, or non-Title I schools. There is a need for a national study exploring the manner with which rural ecological contexts influence children's early learning, especially as children transition from informal care to school. Finally, objective information is needed about the quality of pre-K programs and home environments, which studies have found to be particularly salient for children's outcomes and achievement.

\section{Conclusion}

This study is the first of its kind to provide in-depth information about the ecological contexts of rural Nebraska children. The findings note many areas that are malleable to policies ranging from expansion to more full-day pre-K programs, increased funding for facilities and staff, and greater resources to support the growing diversity and needs of rural Nebraska communities. In addition to uncovering several areas that may be addressed to improve the early learning experiences of pre-K children in Nebraska, there is a need to examine whether the rural context may provide a protective factor for children, especially those from cultural and language minority backgrounds and low-income households.

Acknowledgments - The research reported here was supported by the Institute of Education Sciences, U.S. Department of Education, through Grant R305N160016 to the University of NebraskaLincoln. The opinions expressed are those of the authors and do not represent views of the Institute or the U.S. Department of Education.

\section{Notes}

1. Preschool is used to represent programs for 3- and 4-year-olds, whereas pre-K programs are primarily for 4-year-olds.

2. Per Nebraska statute, English language learner is defined as: A limited English proficient student is a student who was not born in the United States or whose native language is a language other than English; or who is migratory, whose native language is a language other than English, and who comes from an environment where a language other than English is dominant; and whose difficulties in speaking, reading, writing, or understanding the English language may be sufficient to deny the individual the ability to achieve in a classroom taught in English, the ability to score proficient on the state assessment, and/or the opportunity to participate fully in society.

3. $100 \%$ of the federal poverty threshold is defined as an annual income of $\$ 25,100$ for a family of four (https://aspe.hhs.gov/poverty-guidelines). 


\section{References}

Annie E. Casey Foundation. (2013). A two-generation approach to strengthening families. Atlanta, GA: Author.

Appleyard, K., Egeland, B., van Dulmen, M. H. M., \& Sroufe, L. A. (2005). When more is not better: The role of cumulative risk in child behavior outcomes. Journal of Child Psychology and Psychiatry, 46(3), 235-245. http://dx.doi.org/10.1111/j.1469-7610.2004.00351.x

Atkinson, L., Beitchman, J., Gonzalez, A., Young, A., Wilson, B., Escobar, M., \& Villani, V. (2015). Cumulative risk, cumulative outcome: A 20-year longitudinal study. PLoS One, 10(6), e0127650. http://dx.doi.org/10.1371/journal.pone.0127650

Bauch, P. A. (2001). School-community partnerships in rural schools: Leadership, renewal, and a sense of place. Peabody Journal of Education, 76(2), 204-221.

Blair, C. (2010). Stress and the development of self-regulation in context. Child Development Perspectives, 4(3), 181-188. http://dx.doi.org/10.1111/j.1750-8606.2010.00145.x

Bronfenbrenner, U., \& Evans, G. W. (2000). Developmental science in the 21st century: Emerging questions, theoretical models, research designs, and empirical findings. Social Development, 9(1), 115-125. http://dx.doi.org/10.1111/1467-9507.00114

Burchinal, M. (2018). Measuring early care and education quality. Child Development Perspectives, 12(1), 3-9. http://dx.doi.org/10.1111/cdep.12260

Chung, E. K., Siegel, B. S., Garg, A., Conroy, K., Gross, R. S., Long, D. A., \& Fierman, A. H. (2016). Screening for social determinants of health among children and families living in poverty: A guide for clinicians. Current Problems in Pediatric and Adolescent Health Care, 46(5), 135-153. http://dx.doi.org/10.1016/j.cppeds.2016.02.004

Collins, D. (2003). Pretesting survey instruments: An overview of cognitive methods. Quality of Life Research, 12, 229-238.

Curry, J. R., \& O'Brien, E. R. (2012). Shifting to a wellness paradigm in teacher education: A promising practice for fostering teacher stress reduction, burnout resilience, and promoting retention. Ethical Human Psychology and Psychiatry, 14(3), 178-191.

De Marco, A., \& Vernon-Feagans, L. (2013). Rural neighborhood context, child care quality, and relationship to early language development. Early Education and Development, 24(6), 792-812. http://dx.doi.org/10.1080/10409289.2013.736036

Dobbins, D., Tercha, J., McCready, M., \& Liu, A. (2016). Child care deserts: Developing solutions to child care supply and demand. Washington, DC: Child Care Aware of America.

Dubay, L., \& Holla, N. (2015). Absenteeism in DC Public Schools early education program. The Urban Institute.

Durham, R. E., \& Smith, P. J. (2006). Nonmetropolitan status and kindergartners' early literacy skills: Is there a rural disadvantage? Rural Sociology, 71, 625-661.

Economic Research Service. (2017). Rural education at a glance (2017 edition).Washington, DC: United States Department of Agriculture.

Ehrlich, S. B., Gwynne, J. A., Pareja, A. S., \& Allensworth, E. M. (2014). Preschool attendance in Chicago Public Schools. Chicago, Il: University of Chicago.

Flora, C. B., Flora, J. L., \& Gasteyer, S. P. (2018). Rural communities: Legacy and change. New York, NY: Routledge. 
IRUKA ET AL., EARLY CHILDHOOD RESEARCH QUARTERLY 52 (2020)

FLP Key Investigators. (2013). Cumulative risk and its relation to parenting and child outcomes at 36 months. Monographs of the Society for Research in Child Development, 78(5), 66-91. http://dx.doi.org/ 10.1111/mono.12051

Friedman-Krauss, A. H., Raver, C. C., Morris, P. A., \& Jones, S. M. (2014). The role of classroom-level child behavior problems in predicting preschool teacher stress and classroom emotional climate. Early Education and Development, 25(4), 530-552. http://dx.doi.org/10.1080/10409289.2013.817030

Galindo, C., \& Sheldon, S. B. (2012). School and home connections and children's kindergarten achievement gains: The mediating role of family involvement. Early Childhood Research Quarterly, 27(1), 90-103. http://dx.doi.org/10.1016/j.ecresq.2011.05.004

Glaser, B., \& Strauss, A. (1967). Grounded theory: The discovery of grounded theory. Sociology: The Journal of the British Sociological Association, 12, 27-49.

Greenwald, R., Hedges, L. V., \& Laine, R. D. (1996). The effect of school resources on student achievement. Review of Educational Research, 66(3), 361-396. http://dx.doi.org/10.3102/00346543066003361

Hall-Kenyon, K. M., Bullough, R. V., MacKay, K. L., \& Marshall, E. E. (2014). Preschool teacher wellbeing: A review of the literature. Early Childhood Education Journal, 42(3), 153-162.

Hanson, J. L., Hair, N., Shen, D. G., Shi, F., Gilmore, J. H., Wolfe, B. L., \& Pollak, S. D. (2013). Family poverty affects the rate of human infant brain growth. PLoS One, 8(12), e80954. http://dx.doi.org/ 10.1371/journal.pone.0080954

Holmes, S. R., Witte, A. L., \& Sheridan, S. M. (2017). Conjoint behavioral consultation in rural schools. In K. Michael \& J. Jameson (Eds.), Handbook of rural school mental health (pp. 261-274). New York, NY: Springer.

Jeon, L., Buettner, C. K., \& Hur, E. (2014). Family and neighborhood disadvantage, home environment, and children's school readiness. Journal of Family Psychology, 28(5), 718-727. http://dx.doi.org/ 10.1037/fam0000022

Jimenez, M. E., Wade, R., Lin, Y., Morrow, L. M., \& Reichman, N. E. (2016). Adverse experiences in early childhood and kindergarten outcomes. Pediatrics, 137(2), e20151839. http://dx.doi.org/10.1542/ peds.2015-1839

Lichter, D. T. (2012). Immigration and the new racial diversity in rural America. Rural Sociology, 77(1), 3-35. http://dx.doi.org/10.1111/j.1549-0831.2012.00070.x

Lichter, D. T., Parisi, D., Taquino, M., \& Beaulieu, B. (2008). Race and the micro-scale spatial concentration of poverty. Cambridge Journal of Regions Economy and Society, 1, 51-67.

Lincoln, Y. S., \& Guba, E. G. (1985). Naturalistic inquiry (Vol. 75) Thousand Oaks, CA: Sage.

Luby, J., Belden, A., Botteron, K., Marrus, N., Harms, M. P., Babb, C., Nishino, T., \& Barch, D. (2013). The effects of poverty on childhood brain development: The mediating effect of caregiving and stressful life events. JAMA Pediatrics, 167(12), 1135-1142. http://dx.doi.org/10.1001/jamapediatrics .2013 .3139

Malik, R., Hamm, K., Schochet, L., Novoa, C., Workman, S., \& Jessen-Howard, S. (2018). America's child care deserts in 2018. Washington, DC: Center for American Progress.

Matsudaira, J. D., Hosek, A., \& Walsh, E. (2012). An integrated assessment of the effects of Title I on school behavior, resources, and student achievement. Economics of Education Review, 31(3), 1-14.

McCulloch, A., \& Joshi, H. E. (2001). Neighbourhood and family influences on the cognitive ability of children in the British National Child Development Study. Social Science E Medicine, 53, 579-591.

Miller, P., \& Votruba-Drzal, E. (2013). Early academic skills and childhood experiences across the urban-rural continuum. Early Childhood Research Quarterly, 28(2), 234-248. http://dx.doi.org/10.1016/ j.ecresq.2012.12.005 
Monk, D. H. (2007). Recruiting and retaining high-quality teachers in rural areas. The Future of Children, 17(1), 155-174.

Monroe, P. A., \& Tiller, V. V. (2001). Commitment to work among welfare-reliant women. Journal of Marriage and Family, 63, 816-828.

National Academies of Sciences, Engineering, and Medicine (NASEM). (2016). Parenting matters: Supporting parents of children ages $0-8$. Washington, DC: The National Academies Press. http://dx.doi .org/10.17226/21868

Perry, L. B., \& McConney, A. (2010). Does the SES of the school matter? An examination of socioeconomic status and student achievement using PISA 2003. Teachers College Record, 112(4), 1137-1162.

Phillips, D. A., Lipsey, M. W., Dodge, K. A., Haskins, R., Bassok, D., Burchinal, M. R., . . \& Weiland, C. A. (2017). The current state of scientific knowledge on pre-kindergarten effects. Washington, DC: Brookings and Duke University.

Presser, S., Couper, M. P., Lessler, J. T., Martin, E., Martin, J., Rothgeb, J. M., \& Singer, E. (2004). Methods for testing and evaluating survey questions. Public Opinion Quarterly, 68, 109-130.

Provasnik, S., Kewalramani, A., Coleman, M. M., Gilbertson, L., Herring, W., \& Xie, Q. (2007). Status of education in rural America (NCES 2007-040). Washington, DC: U.S. Department of Education, Institute of Education Sciences, National Center for Education Statistics.

Randolph, J. J. (2005). Free-marginal multirater kappa: An alternative to Fleiss' fixed-marginal multirater kappa. Paper presented at the Joensuu University Learning and Instruction Symposium 2005, Joensuu, Finland, October 14-15, 2005.

Randolph, J. J. (2008). Online kappa calculator. Retrieved from http://justus.randolph.name/kappa

Roberts, A. M., Iruka, I. U., \& Sarver, S. L. (2017). Nebraska early childhood workforce report. Omaha, NE: University of Nebraska, Buffett Early Childhood Institute.

Sameroff, A. J., Bartko, W. T., Baldwin, A., Baldwin, C., \& Seifer, R. (1998). Family and social influences on the development of child competence. In M. Lewis \& C. Feiring (Eds.), Family, risk, and competence (pp. 161-185). Mahwah, NJ: Lawrence Erlbaum Associates Publishers.

Schafft, K. A. (2006). Poverty, residential mobility, and student transiency within a rural New York school district. Rural Sociology, 71(2), 212-231. http://dx.doi.org/10.1526/003601106777789710

Schafft, K. A. (2005). The incidence and impacts of student transiency in upstate New York's rural school districts. Journal of Research in Rural Education, 20(15), 1-13.

Semke, C. A., \& Sheridan, S. M. (2012). Family-school connections in rural educational settings: A systematic review of the empirical literature. School Community Journal, 22(1), 21-47.

Shonkoff, J. P., Garner, A. S., \& The Committee on Psychosocial Aspects of Child Family Health, C.o.E.C. (2012). The lifelong effects of early childhood adversity and toxic stress. In B. S. Siegel, M. I. Dobbins, M. F. Earls, \& D. L. Wood (Eds.), Adoption, Dependent Care, Section on Developmental Behavioral Pediatrics, Pediatrics, 129(1), e232-e246. http://dx.doi.org/10.1542/peds.2011-2663

Showalter, D., Klein, R., Johnson, J., \& Hartman, S. L. (2017). Why rural matters 2015-2016: Understanding the changing landscape. Washington, DC: Rural School and Community Trust.

Smith, M. D., \& Krannich, R. S. (2000). “Culture Clash” revisited: Newcomer and longer-term residents' attitudes toward land use, development, and environmental issues in rural communities in the Rocky Mountain West. Rural Sociology, 65(3), 396-421. http://dx.doi.org/10.1111/j.1549-0831 .2000.tb00036.x

Smith, M., Patterson, K., \& Doggett, L. (2008). Meeting the challenge of rural pre-k. Washington, DC: Pre-Know. 
Vandell, D. L., Belsky, J., Burchinal, M., Steinberg, L., Vandergrift, N., \& NICHD Early Child Care Research Network. (2010). Do effects of early child care extend to age 15 years? Results from the NICHD Study of Early Child Care and Youth Development. Child Development, 81(3), 737-756. http://dx.doi.org/10.1111/j.1467-8624.2010.01431.x

Vernon-Feagans, L., \& Cox, M. (2013). I. Poverty, rurality, parenting, and risk: An introduction. Monographs of the Society for Research in Child Development, 78(5),1-23. http://dx.doi.org/10.1111/ mono. 12047

Voices for Children in Nebraska. (2018). Kids count report in Nebraska, 2018. Omaha, NE: Author.

Warrens, M. J. (2010). Inequalities between multi-rater kappas. Advances in Data Analysis and Classification, 4(4), 271-286.

Weiland, C., Ulvestad, K., Sachs, J., \& Yoshikawa, H. (2013). Associations between classroom quality and children's vocabulary and executive function skills in an urban public prekindergarten program. Early Childhood Research Quarterly, 28(2), 199-209. http://dx.doi.org/10.1016/j.ecresq.2012.12.002 